6. Kholopova, V. (1990). Music as a form of art. M.: Scientific and Creative Center «Conservatory» [in Russian].

7. Kholopova, V. (1983). Musical themes: [Scientific and methodological essay. M. [in Russian].

8. Kholopova, V. (2002). Special and non-special musical content. Moscow: Izdatelstvo MGK im. P. I. Tchaikovsky [in Russian].

9. Kholopova, V. (1999). Forms of musical works: [Textbook]. St. Petersburg: Lan [in Russian].

Стаття надійшла до редакції 22.06.2016

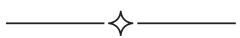

УДК 781.65

Чжу Веньфен, ассистент-стажер кафедры сольного пения

Одесской национальной музыкальной академии им. А. В. Неждановой

\title{
АКТУАЛЬНЫЕ МУЗЫКОВЕДЧЕСКИЕ ПОДХОДЫ К ЯВЛЕНИЮ МУЗЫКАЛЬНОЙ РИТОРИКИ
}

Целью данной статьи является осуществление анализа сущности риторики как многогранного феномена и выявление специфики ее развития на разных историко-культурных этапах, а также исследование модификации взглядов на музыкальную риторику. Методология работы опирается на историко-библиографический метод, привлекаются системный, компаративный и аналитический подходы. Научная новизна работы заключается в расширении представлений о музыкальной риторике как о семиотико-культурологической области научных интересов музыковедения; в изучении логики и причин изменений научного знания по отношению $\kappa$ музыкальной риторике; в попытке обобщений наиболее актуальных разработок проблем музыкальной риторики. Выводы. Устанавливается широта грании, музыкальной риторики, многообразие подходов к этому феномену, многоаспектность его восприятия и научно-исследовательской оценки, также указывается на невыстроенность, несогласованность основных позиций музыкальной риторики. Обращается внимание на то, что исследование музыкальной риторики с точки зрения теории языка и музыкально-речевой деятельности, то есть с семиотической позиции, в современный период приобретает характер устойчивой $и$ постоянно развивающейся тенденции. Актуализируется понимание музыкальной риторики как выстраивающей определенную семиотическую модель музыки, в которой за основу принимается особая образно-смыс-

(C) Чжу Веньфен, 2016 
ловая единица - музыкально-риторическая фигура - своеобразная композиционно-звуковая идиома.

Ключевые слова: общая риторика, музыкальная риторика, риторика формы, музыкально-риторическая фигура, семиотическая модель.

Zhu Venfen, assistant-trainee of solo singing department Odessa national Music Academy. A. V. Nezhdanova

Actual musicological approaches to the phenomenon of musical rhetoric

The purpose of this article is to analyze the essence of rhetoric as a multifaceted phenomenon and to identify the specifics of its development at different historical and cultural stages, as well as to study the modification of views on musical rhetoric. The research methodology is based on the historical-bibliographic method, systemic, comparative and analytical approaches are attracted. The scientific novelty of the work is to expand the notion of musical rhetoric as a semiotics-culturological field of the scientific interests of musicology; in the study of logic and the causes of changes in scientific knowledge in relation to musical rhetoric; in an attempt to generalize the most relevant developments of the problems of musical rhetoric. Conclusions. The breadth of the boundaries of musical rhetoric, the diversity of approaches to this phenomenon, the multidimensional nature of its perception and research evaluation are also established, and the non-alignment, inconsistency of the basic positions of musical rhetoric is also pointed out. Attention is drawn to the fact that the study of musical rhetoric from the point of view of the theory of language and musical-speech activity, that is, from the semiotic position, in the modern period acquires the character of a stable and constantly evolving trend. The understanding of musical rhetoric as building a certain semiotic model of music is being actualized, in which a special figurative and semantic unit is taken as the basis - a musical-rhetorical figure - a peculiar composition-sound idiom.

Keywords: general rhetoric, musical rhetoric, form rhetoric, musical-rhetorical figure, semiotic model.

Чжу Веньфен, асистент-стажист кафедри сольного співу Одеської національної музичної академії ім. А. В. Нежданової

Актуальні музикознавчі підходи до явища музичної риторики

Метою даної статmі $\epsilon$ здійснення аналізу сутності риторики як багатогранного феномена та виявлення специфіки ї̈ розвитку на різних історико-культурних етапах, а також дослідження модифікації поглядів на музичну риторику. Методологія роботи спирається на історико-бібліографічний метод, залучаються системний, компаративний та аналітичний підходи. Наукова новизна роботи полягає: в розширенні уявлень про музичну риторику як про семіотико-культурологічну галузь наукових інтересів музикознавства; у вивченні логіки та причин змін наукового знання по відношенню до музичної риторики; в спробі узагальнень найбільш актуальних розробок проблем музичної риторики. Висновки. Вста- 
новлюеться широта меж музичної риторики, різноманіття підходів до цього феномена, багатоаспектність його сприйняття та науково-дослідницької оцінки, також вказується на неузгодженість основних позицій музичної риторики. Звертається увага на те, що дослідження музичної риторики з точки зору теорії мови та музично-мовленнєвої діяльності, тобто з семіотичної позиції, в сучасний період набуває характеру стійкої тенденції, що постійно розвивається. Актуалізується розуміння музичної риторики як тієї, що вибудовує певну семіотичну модель музики, в якій за основу береться особлива образно-смислова одиниия музично-риторична фігура - своєрідна композиційно-звукова ідіома.

Ключові слова: загальна риторика, музична риторика, риторика форми, музично-риторична фігура, семіотична модель.

Актуальность темы исследования. В современном музыковедении неизменную глубокую заинтересованность вызывают проблемы изучения содержания музыки и приемов его реализации. Исследование соотношения между содержанием и средствами музыки может изучаться либо со стороны средств, способных служить достижением данного содержательно-выразительного эффекта, либо со стороны содержательно-выразительных эффектов, осуществлению которых способно служить данное средство. В любом случае одним из наиболее перспективных методов решения данной проблемы становится обращение к риторике, которая, с одной стороны, упорядочивает выражение содержания в обычной речи, а с другой, лежит в основе особой системы музыкальных средств, получившей название музыкальной риторики.

Риторика является необходимой стороной «функционирования любой языковой системы и особенно важна в искусстве в силу образной предназначенности и образной регламентации его языковых средств» [9]. Поэтому так важно определение путей музыкально-риторического знания, что позволило бы нам, прежде всего, приблизиться к глубинным установкам, формирующим соответствующие феномены искусства и культуры в целом. Также актуальность нашего исследования видится и в возможности рассмотреть феномен риторики в музыкальном восприятии как научно-теоретическую проблему, тем более что это явление еще недостаточно полно изучено в отечественном музыкознании.

Анализ исследований и публикаций. Теоретической базой данной статьи служат исследования, сгруппированные по двум основным «блокам» проблем: во-первых, связанные с общей риторикой и освещающие ее с точки зрения историографии (В. Голубев [4], В. Топоров 
[11],), либо концентрирующиеся на избранных аспектах этого явления (С. Аверинцев [1], М. Гаспаров [3], У. Эко [14]); во-вторых, рассматривающие вопросы музыкальной риторики как общетеоретического плана (М. Арановский [2], А. Самойленко [10], В. Холопова [12; 13] и др.), так и в связи с определенными эпохами, стилевыми направлениями и композиторами (О. Захарова [7], С. Дружинин [5], Я. Друскин [6], Ю. Кон [8], Д. Присяжнюк [9] и др.).

Целью данной статьи является осуществление анализа сущности риторики как многогранного феномена и выявление специфики ее развития на разных историко-культурных этапах, а также исследование модификации взглядов на музыкальную риторику.

Изложение основного материала. Риторика (от греч. rhetorike течь, литься) существует тысячи лет. Это понятие ассоциируется в первую очередь с искусством красноречия, умением изложить мысль ясно, убедительно, выразительно и «красиво». Владение словом всегда высоко ценилось и рассматривалось как часть общей культуры человека. Риторика же разработала развитую систему правил создания речи, выбора ее материала, направленных на рациональное выражение явлений жизни. По мнению М. Гаспарова, риторика учила человека расчленять словом окружающий мир, «выделять в нем темы, подтемы, мотивы, разбивать их по смежности и сходству, размещать и связывать их в гармонически стройные конструкции» $[3,55]$.

Центром интересов риторики были и есть способы построения художественно выразительной речи, прежде всего прозаической и устной. Здесь риторика противостоит и поэтике, изучающей поэтическую речь, и грамматике, ориентированной на изучение «естественной» (эстетически неотмеченной) речи, и герменевтике, имеющей дело с пониманием текста. Однако это не означает отсутствие пересечений между названными сферами гуманитарного знания. Так, например, можно отметить, что между риторикой и герменевтикой существует тесная связь: при прочтении художественного произведения читатель вступает в диалог с автором через текст, а восприятие и осмысление становятся герменевтическим последствием риторики, ее своеобразным отзвуком.

Риторика как наука убеждать (отметим сразу, что данная формула риторики выдвигалась Аристотелем и Аполлодором, в теории римского красноречия, например, более популярной стала квинтэссенция Квинтилиана о риторике как об искусстве говорить хорошо, то есть впечатлять [4]) выполняет масштабную задачу: трансформирует 
предметы и явления в слово, а это означает, что в центр риторической концепции в целом поставлен человек говорящий - homologuens. Таким образом, риторика возложила на себя контроль за всеми стадиями процесса трансформации предмета в слово. Таких стадий в классической риторике пять (inventio, dispositio, elocutio memona, actio) и все они базируются на общем фундаменте persuasio, что переводится с латыни как убеждение, поэтому риторика, о чем мы сказали выше, часто трактуется как наука об убеждении, или наука убеждать.

Античная риторика была усвоена в средневековье и пользовалась большим престижем, входя в число семи «избранных наук». Эпоха Возрождения и следовавшие за ней периоды господства отдельных художественных направлений (маньеризм, барокко, классицизм) уделяли риторике значительное внимание, чему свидетельством становятся многочисленные французские, немецкие, итальянские (и не только) трактаты XVI-XVIII веков. В это время, особенно в XVII веке, риторика, с одной стороны, тяготеет к универсализации, обнаруживая связи со складывающейся «логической» грамматикой, а с другой, превращается в инструмент, способный уловить достаточно тонкую дифференциацию эстетических установок [4].

В эпоху романтизма риторика с ее нормативно-дидактическими тенденциями начинает восприниматься как изживший себя канон, препятствующий свободному творчеству, как дисциплина схоластически-катологизаторского типа, не способная проникнуться идеями историзма, препятствующая новым принципам словесного искусства и как наука приходит к началу XIX века в состояние упадка. Однако с 1960-х гг. вновь начинается расцвет риторического знания, нашедший для себя новый идейно-научный контекст. Она становится одной из наиболее быстро и продуктивно развивающихся дисциплин филологического цикла. Этот период в истории риторического знания нередко называют «неориторикой» или «общей риторикой» (rhetorique generale). Становление риторики нового типа вызвано в первую очередь лингвистическими факторами, через которые она включается в круг семиотических дисциплин и в сферу культурологических проблем.

Умберто Эко в «Отсутствующей структуре» пишет: «Риторика не описывает из ряда вон выходящие случаи риторических фигур, которых не может предположить никакой набор психологических или каких-либо других ожиданий, она описывает только те приемы, пусть весьма неожиданные, которые набор слушательских ожиданий все- 
таки может вместить. В отличие от поэтического дискурса, который, базируясь на минимальных дозах избыточности (в минимальной степени принимая во внимание ожидания адресата), побуждает потребителя к усилию истолкования, к переоценке кодов, - и это одна из существеннейших характеристик современного искусства, - риторика, отвергая крайности, закрепляет взвешенный тип речи, управляемую неожиданность» [14, 129]. Столь продолжительная цитата понадобилась не только для того, чтобы продемонстрировать нетривиальный подход У. Эко к феномену риторики, но и указать на широкое понимание автором риторики как лингвистической прагматики, или речеведения в целом.

Представленный исторический взгляд на бытование риторики помогает прийти к следующим выводам:

- во-первых, риторика как наука исследует многовековую культуру действенного слова. Риторика является одновременно искусством речи и теорией этого искусства, научной дисциплиной, основанной на богатой культурной традиции;

- во-вторых, поскольку в центр риторической концепции в целом поставлен человек говорящий - homo loguens, что указывает на антропологический срез этой сферы научного знания, риторика может восприниматься и как оптимизирующий механизм человеческого общения (как «набор правил, требуемых организацией духовного существа» $[7,12])$, через который передаются культурные смыслы и человеческая символика;

- в-третьих, налицо многофункциональность риторики, которая обеспечила ей существование в новых современных условиях, что позволяет говорить об универсальности риторического знания, для которого характерен особый «подход к обобщению действительности» [1];

- в-четвертых, если рассматривать риторику как речеведение в целом, как изучение феноменализации языка в социуме, то становится очевидным, что ее область является важнейшей частью теории социальной коммуникации.

Музыкальная риторика значительно младше общей. Если общая риторика с самого начала понималась как практическая наука, дающая теоретическое обоснование своим положениям, то музыкальная риторика, напротив, долгое время оставалась лишь набором правил сочинения музыки, соотнесенных с риторикой в наиболее общем отношении. Тем не менее, в историческом развитии музыкальной и общей риторик присутствуют совместные моменты. К одним из 
таких пересечений можно по праву отнести, например, то, что XIX век, также как и для обычной риторики, прошел без особо активного развития этой науки. Кроме того, нельзя не отметить и последующий всплеск в развитии музыкально-риторического знания, связанный XX столетием. Этот факт очевиден и для общей риторики.

Историческое развитие риторики, по мысли В. Топорова, переживает два этапа - «классический», отмеченный становлением и последующим угасанием ее культурогенных функций, и «неориторический» (с 1960-х гг.), когда риторика «включается в круг семиотических дисциплин» и реактуализирует «сферу культурологических проблем» $[11,417]$. Интенсивное возрождение риторики в XX веке связано с ее широким распространением в социокультурной среде и проявлением своей практической сущности в процессах современной коммуникации. Предпосылки именно такого развития отмечены О. Захаровой, одной из авторитетнейших исследовательниц музыкальной риторики: «Риторика сыграла важную роль в закреплении семантики, выработке музыкального «лексикона», впервые с такой полнотой и силой раскрывшего возможности музыки как выразительного языка... В этом смысле музыкальную риторику действительно можно считать исторической предшественницей семиотического метода в музыковедении» [7, 9].

Индивидуальный вектор развития в области музыкальной риторики связан с авторскими подходами к этому явлению. Так первый значительный круг исследователей, которые в своих трудах уделяют внимание развитию музыкально-риторических приемов, появляется на протяжении XVII века. Трактаты И. Бурмейстера, А. Кирхера, И. Бернхардта, И. К. Принтца и др. дают общие сведения о расположении материала по аналогии с правилами расположения материала античной речи. Заслугой перечисленных авторов становится также определение тезауруса музыкально-риторических фигур, которые суммировали предшествующий композиторский опыт. Кроме того, в некоторых трактатах высказываются суждения о связи приемов музыкальной риторики с выражением музыки разных стилей (И. Бернхардт) [5].

Собственно наукой музыкальная риторика становится позже, в баховскую эпоху, когда были обобщены ее результаты, принципы, выработана классификация приемов. Принципы музыкальной риторики и их эстетическая оценка наиболее четко были сформулированы И. Маттезоном. Им была создана классификация музыкальных 
фигур, обращающаяся к античной риторике, определение более развитой схемы музыкального материала и роли риторических акцентов в его репрезентации [5].

Дальнейший этап в развитии музыкальной риторики связан с именем И. Форкеля. Он рассматривал музыкальную риторику как единую систему, приемы которой, в отличие от музыкальной риторики И. Маттезона, наблюдаются только на примерах инструментальной музыки.

XX столетие породило новую волну интереса к музыкальной риторике. А. Швейцер, Б. Яворский не используют риторических терминов при изучении музыки И. С. Баха, но рассматривают значение мотивов-символов в вокально-хоровом и камерно-инструментальном жанрах немецкого композитора, что представляет актуальный для музыкальной риторики аспект.

Приведенный далее обзор методологических подходов к явлению музыкальной риторики на современном этапе указывает не только на многоаспектность проблематики этого феномена, но и обуславливает две магистральные линии исследовательских путей в рамках заявленного.

Первая линия представлена немногочисленными трудами, ценность которых в непосредственном рассмотрении основных аспектов музыкально-риторического знания. К ним можно отнести монографию Я. Друскина «О риторических приемах в музыке И. С. Баха». Автор подробно характеризует музыкально-риторические фигуры в творчестве немецкого композитора (разрабатывает собственную классификацию мотивов фигур (мотивы обхода, отталкивания и т. д.)), диспозиции, риторические акценты. Последнее музыковед рассматривает с точки зрения художественных возможностей в музыкально-риторическом высказывании, что помогает исполнить музыку композитора аутентично, в соответствии с художественной практикой его эпохи [6].

Еще одной работой, презентующей первое направление, становится «Риторика и западноевропейская музыка XVII - первой половины XVIII века» О. Захаровой, в которой подробно рассматриваются традиционные риторические фигуры и особенности их семантического прочтения. К ним относятся как классификация фигур, изучение принципов риторики в западноевропейской музыке XVII XVIII веков, так и исследование приемов музыкальной риторики в музыке Г. Шютца и в клавирной музыке XVIII века [7]. 
Вторая линия представлена целым рядом статей, исследовательская мысль в которых занята изучением отдельных, однако не менее серьезных аспектов музыкальной риторики.

Внутри этого направления научные первоисточники можно дифференцировать по следующим параметрам: статьи, сконцентрированные на творчестве конкретной персоналии, и компаративные работы, не ограничивающие себя рассуждениями о поэтике одного автора. Общим для обеих линий становится наличие значительных теоретических рассуждений.

Ярким подтверждением первого направления становятся статьи А. Кандинского-Рыбникова, В. Штейнгардта, Л. Кириллиной, Е. Чигаревой; второго - И. Барсовой, В. Холоповой, М. Катунян, М. Лобановой, Ю. Петрова и др.

Так, характерные интонации, выраженные в музыкально-риторических фигурах, реализующих словесный текст музыкальных произведений, рассматриваются в контексте творчества В. Моцарта (Е. Чигарева), Л. Бетховена (Л. Кириллина), Г. Шютца (В. Штейнгардт), вопросы художественно-риторической формы акцентируются в рамках жанра клавирной сонаты в творчестве Д. Скарлатти (Ю. Петров, А. Кандинский-Рыбников). К последним можно отнести и работу В. Холоповой «О прототипах функций музыкальной формы», в которой диспозиция рассматривается как прототип классической сонатной формы. Здесь изучаются также вопросы соотношения общекомпозиционных функций и разделов расположения музыкального материала. Такое исследование позволяет сделать вывод о связи риторики с формированием классической музыкальной формы [13].

В области художественно-риторической формы ценна статья Ю. Кона «Священное песнопение» И. Стравинского. В ней музыковед вводит понятие «риторика формы», обозначающее компонент музыкально-риторического высказывания, который обусловлен риторической диспозицией. Ю. Кон отмечает значимость риторики формы в создании «особого эмоционально-художественного тонуса, направленно достигаемого в рамках целостного произведения». Этот тонус выражен через «вовлечение в одно произведение различных исторических музыкальных стилей» - венецианской полифонической школы XVI века и серийной музыки XX века. Средства разных исторических стилей составляют содержание разных частей риторики формы и тем самым выражают убеждение музыкально-риториче- 
ского высказывания «о совершенно особом установлении, о форме мира», о его вечности [8].

В исследованиях М. Лобановой и Ю. Петрова проблема музыкальной риторики соприкасается с категориями эстетики, поэтики, языка, слова, смысла, элементами математики. Приемы музыкальной риторики рассматриваются во взаимодействии с принципами репрезентации, антитезы, игры, характерными для стилевой и жанровой системы музыкального барокко.

Продолжением темы (на ином материале) служат аналитические статьи И. Барсовой, где поднимается принципиальный вопрос о существовании риторического типа творчества, рассматривается проблема этимологии риторических фигур, а собственно риторическая традиция свободно «инкрустируется» в исторический контекст, представая живым, мобильным.

Текстологический срез музыкальной риторики презентует исследование М. Арановского «Музыкальный текст: структура и свойства». Автор изучает в своем труде принципы функционирования музыкальных структур, воздействующих на слушателя «независимо от рефлексии». Проблема современного семантического прочтения риторических фигур, воспринимаемых профессионалами в русле сознательного (или спонтанного) рефлектирования.

Исследователь, теоретически рассуждая о специфике музыкального текста, отмечал, что все музыкальные тексты образуют особую «вертикальную парадигматическую структуру, где каждый новый текст эквивалентен (по определенным признакам) предшествующим», «музыкальные тексты (и произведения)... не продолжают, а повторяют друг друга» [2, 76-77]. Данные рассуждения обнаружили определенную закономерность появления в музыкальном тематизме устойчивых стереотипных образований, которые сохраняют круг изначально заданных значений при включении в различные художественные контексты. Эти образования получили название мигрирующих интонационных формул. Кроме того, М. Арановский выявляет механизм образования таких стереотипов в бытовой среде, который проявляется через повторность определенных «этикетных формул» [2, 106-107]. Музыковед также проводит дифференциацию стереотипных структур и делит на контекстуальные (например, лейтмотив) и внетекстовые: признаки жанров (например, пунктирные маршевые ритмы, раскачивающиеся мелодические фигурации колыбельной, специфическая аккордовая фактура хорала и так далее), отдельные 
обороты с фиксированной выразительностью, типичные для определенного музыкального стиля или индивидуального оркестрового письма [2].

Охарактеризованные методологические подходы далеко не исчерпываются представленными работами. На рубеже XX и XXI веков появляется значительный ряд исследований, которые рассматривают вопросы, касающиеся образов, внемузыкальных понятий, выраженных в музыкальных фигурах; изучают приемы артикуляции, объясняемые как особые фигуры музыкальной риторики, и действие музыкально-риторических приемов на возможности исполнения; указывают на происхождение музыкально-риторических фигур от мигрирующих интонациональных формул, которые в свою очередь обусловлены интонациями обычной речи и т. п. Среди них работы И. Розановой, А. Александрова, М. Аркадьева, В. Носиной, Л. Шаймухаметовой, С. Шипа и многих других. Перечисленные музыковедческие подходы позволяет трактовать риторику как систему знаков, ассоциативно связывающих внемузыкальные смыслы с его звуковым прообразом на основе кода, обладающего определенными структурно-семантическими функциями и выполняющего коммуникативную функцию в передаче информации от композитора к слушателю, от композитора к исполнителю и от исполнителя к слушателю.

Результаты изучения феномена музыкальной риторики с точки зрения актуальных музыковедческих подходов позволяют говорить о:

- широте границ этой семиотико-культурологической области научных интересов музыковедения, в кругу которой оказываются ученые, имеющие разные позиции, а следовательно, о многообразии представленных подходов, многоаспектности восприятия и научноисследовательской оценки, а также о невыстроенности, несогласованности основных позиций музыкальной риторики;

- интердисциплинарной направленности музыкознания XX начала XXI века, что обуславливает его активное взаимодействие со смежными науками, среди которых первенство по праву принадлежит лингвистике. Исследование риторики с точки зрения теории языка и музыкально-речевой деятельности, то есть с семиотической позиции, в современный период приобретает характер устойчивой и постоянно развивающейся тенденции;

- выстраивании определенной семиотической модели музыки, помещенной в широкий информационно-знаковый контекст, в ко- 
торой за основную категорию принимается особая образно-смысловая единица;

- рассмотрении в качестве исходной модели музыкально-риторической фигуры со всеми ее атрибутами - повторяемостью в разных текстах, формульностью, относительно стабильным значением, а также устойчивостью внешней формы, что позволяет подходить к ней как к особой композиционно-звуковой идиоме (интонационному паттерну) для хранения, передачи и обработки информации.

\section{СПИСОК ЛИТЕРАТУРЫ}

1. Аверинцев С. Риторика как подход к обобщению действительности. Поэтика древнегреческой литературы. М.: Наука, 1981. С. 15-46.

2. Арановский М. Музыкальный текст: структура и свойства. М.: Композитор, $1998.343 \mathrm{c}$.

3. Гаспаров М. Средневековые латинские поэтики в системе средневековой грамматики и риторики. Проблемы литературной теории в Византии и латинском средневековье. М., 1986. 257 с.

4. Голубев В. Риторика. Минск: ТетраСистемс, 2008. 224 с.

5. Дружинин С. Система средств музыкальной риторики в оркестровых сюитах И. С. Баха, Г. Ф. Генделя, Г. Ф. Телемана: дис. ... канд. искусствоведения: 17.00.02. / Рос. академия музыки им. Гнесиных. Москва, 2002. 210 с. $132 \mathrm{c}$.

6. Друскин Я. О риторических приемах в музыке И. С. Баха. СПб., 1999.

7. Захарова О. Риторика и западноевропейская музыка XVII - первой половины XVIII века. М.: Музыка, 1983.77 с

8. Кон Ю. «Священное песнопение» («Canticum sacrum») Стравинского и риторика формы. Петрозаводск, 1996. С.16.

9. Присяжнюк Д. Музыкальный риторизм и композиторская практика XX века: дис. канд. искусствоведения: спец. 17.00.02 / Нижегород гос. консерватория им. М. И. Глинки. Нижний Новгород, 2004. 257 с.

10. Самойленко А. Музыковедение и методология гуманитарного знания. Проблема диалога. Одесса: Астропринт, 2002. 244 с.

11. Топоров В. Риторика. Языкознание: Большой энциклопедический словарь/ гл. ред. В. Н. Ярцева. М., 1998. 685 с.

12. Холопова В. Музыка как вид искусства. М.: Научно-творческий центр «Консерватория», 1994. 260 с.

13. Холопова В. О прототипах функций музыкальной формы. Проблемы музыкальной науки.. М. 1979. Вып.4. С.4-22.

14. Эко У. Отсутствующая структура. Введение в семиологию. СПб.: Symposium, 2006. 544 c. 


\section{REFERENCES}

1. Averintsev S. (1981) Rhetoric as an approach to the generalization of reality. Poetics of Ancient Greek Literature. M.: Nauka, 15-46. [in Russian].

2. Aranovsky M. (1998) Musical text: structure and properties. M.: Compositor. [in Russian].

3. Gasparov M. (1986) Medieval Latin poetics in the system of medieval grammar and rhetoric. Problems of literary theory in Byzantium and the Latin Middle Ages. M.[in Russian].

4. Golubev V. (2008) Rhetoric. Minsk: TetraSystems. [in Russian].

5. Druzhinin S. (2002) The system of musical rhetoric in orchestral suites of I. S. Bach, G. F. Handel, G. F. Telemann: dis.... cand. of art history: 17.00.02. / Ros. Academy of Music. Gnessins. Moscva. [in Russian].

6. Druskin Ya. (1999) About rhetorical receptions in music I. S. Bach. SPb., 1999. [in Russian].

7. Zakharova O. (1983) Rhetoric and Western European music XVII - the first half of the XVIII century. M.: Musica. [in Russian].

8. Kon Yu. (1996) «Sacred Canticle» («Canticum sacrum») of Stravinsky and rhetoric of form. Petrozavodsk. 16-. [in Russian].

9. Prisyazhnyuk D. (2004) Musical rhetoric and compositional practice of the twentieth century: dis. Cand. art studies: special. 17.00.02 / Nizhegorod. gos. conservatory of M. I. Glinka. Nizhnyi Novgorod. [in Russian].

10. Samoylenko A. (2002) Musicology and methodology of humanitarian knowledge. The problem of dialogue. Odessa: Astroprint. [in Russian].

11. Toporov V. (1998) Rhetoric. Linguistics: The Great Encyclopedic Dictionary / ch. ed. V. N. Yartseva. M.. [in Russian].

12. Kholopova V. (1994) Music as a form of art. Moscva: Naychno-tvorcheskii centr «Conservatoria». [in Russian].

13. Kholopova V. (1979) About the prototypes of the functions of musical form. Problems of Musical Science. M. Vip. 4. 4-22. [in Russian].

14. Eco U. (2006) The missing structure. Introduction to Semiology. SPb.: Symposium. [in Russian].

Стаття надійщла до редакції 07.06.2016

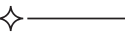

